
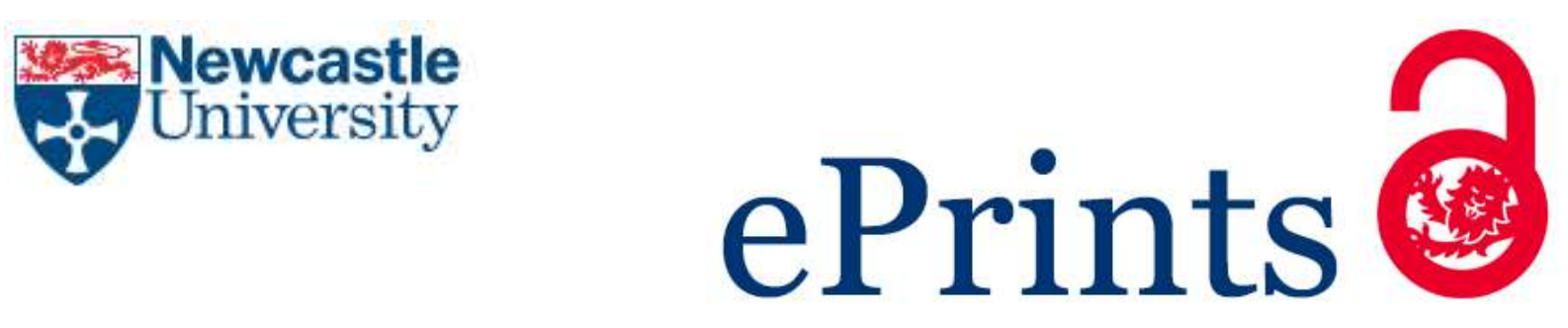

Jenkins AM, Patsios C, Taylor P, Khayrullina A, Chirkin V. Optimising virtual power plant response to grid service requests at newcastle science central by coordinating multiple flexible assets. In: IET Conference Publications. 2016, Helsinki, Finland: Institution of Engineering and Technology.

\title{
Copyright:
}

(C) 2016 IEEE. Personal use of this material is permitted. Permission from IEEE must be obtained for all other uses, in any current or future media, including reprinting/republishing this material for advertising or promotional purposes, creating new collective works, for resale or redistribution to servers or lists, or reuse of any copyrighted component of this work in other works.

DOI link to article:

http://doi.org/10.1049/cp.2016.0812

Date deposited:

$24 / 05 / 2017$ 


\section{OPTIMISING VIRTUAL POWER PLANT RESPONSE TO GRID SERVICE REQUESTS AT NEWCASTLE SCIENCE CENTRAL BY COORDINATING MULTIPLE FLEXIBLE ASSETS}

\author{
Andrew M. Jenkins, Charalampos Patsios, Phil Taylor \\ Newcastle University \\ a.m.jenkins@newcastle.ac.uk
}

\begin{abstract}
Newcastle Science Central is introduced; a 24 acre city centre site being developed as an exemplar sustainable urban environment encompassing Smart Grid technologies throughout. A real time energy management algorithm is proposed to maximise the power availability of the site's flexible electrical assets; all of which have different operating characteristics. Each asset is considered in an equivalent form similar to energy storage, allowing it to be compared on a like-for-like basis through a virtual state of charge. The new Enhanced Frequency Response service offered by National Grid is used as a case study to demonstrate that through intelligent energy management, the site operated as a virtual power plant, can deliver greater value than the sum of the constituent assets operating individually to the same overall control signal.
\end{abstract}

\section{INTRODUCTION}

The UK is targeting reduced carbon emissions of $80 \%$ of 1990 levels by 2050 [1]. The electrical generation industry has responded by transitioning to renewables, which accounts for $77 \%$ of all new power plant installations in Europe [2]. Distributed renewable generation typically has a variable output and is connected at lower voltages closer to the load than traditional dispatchable centralized generation. At high penetrations, the variability of these renewables can cause network issues that must be managed [3] and microgrids have been suggested as a facilitating technology to help integrate many small distributed generators into electrical networks [4].

This paper describes the services that could be delivered to the grid by a microgrid operating as a Virtual Power Plant (VPP) [5]. An exemplar microgrid, Science Central, being built in Newcastle city centre, UK, is introduced, before a control scheme designed to maximize the availability for providing services is described and demonstrated.

\section{VIRTUAL POWER PLANT SERVICES}

A VPP can deliver different services to the grid including; peak shaving or capacity management [6], voltage support [7], Enhanced Frequency Response (EFR) and Firm Frequency Response (FFR) [8], Short-Term Operating Reserve (STOR) [8], capacity market [9] and tolling [10]. This paper considers a VPP response to the EFR service. EFR is a new market to help maintain system frequency and will start operating Winter 2017/18. The required response is dependent upon system frequency, as shown in

\author{
Aliya Khayrullina, Vasily Chirkin \\ Skolkovo Institute of Science and Technology \\ Aliya.khayrullina@skolkovotech.ru
}

Figure 1. The service will allow an envelope of deviation from the set point curve, widening around the normal operating frequency. This is designed to enable State Of Charge (SOC) management, however the magnitude of this range is still to be determined by National Grid. The output must be delivered within $1 \mathrm{~s}$ of being called, and support the grid for at least $9 \mathrm{~s}$ until the primary FFR service can take over.

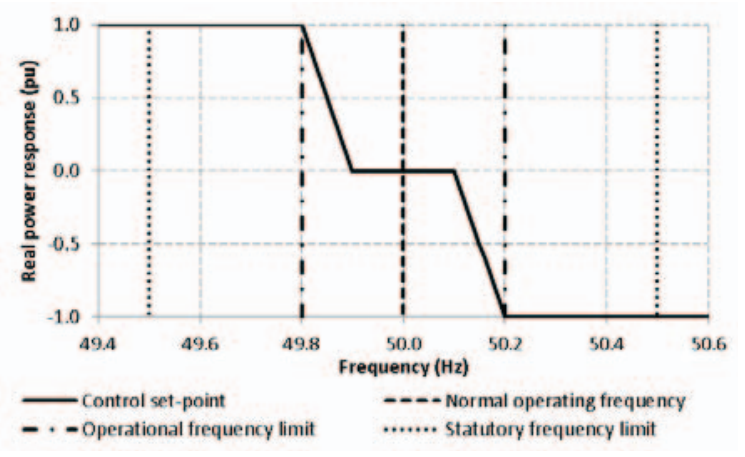

Figure 1: Service requirements for Enhanced Frequency Response [8]

\section{PLANT DESCRIPTION : SCIENCE CENTRAL}

Newcastle University and Newcastle City Council, are collaborating to redevelop a 24 acre city centre brownfield site to be an exemplar sustainable urban environment encompassing Smart Grid technologies throughout [11]. Electrically, the site will contain an Energy Storage System (ESS) [12], an Electric Vehicle (EV) charging station, a Combined Heat and Power (CHP) plant, Photovoltaic (PV) generation and both residential and commercial buildings with the potential to provide Demand Side Response DSR [11]. The proposed electrical distribution of the site is shown in Figure 2.

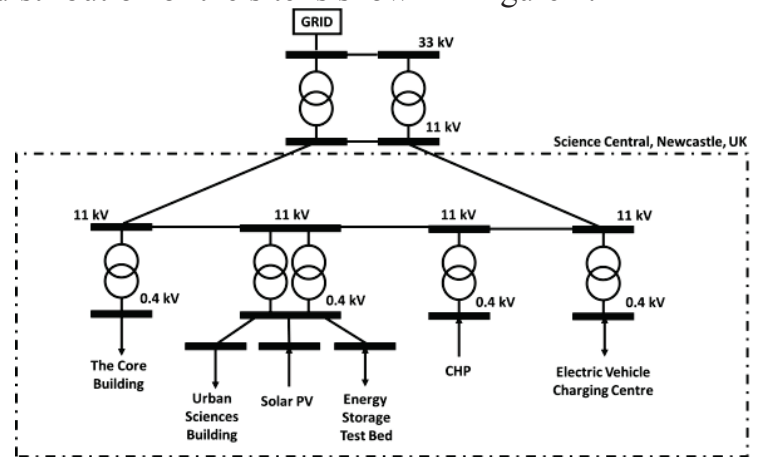

Figure 2: Proposed electrical distribution of phase 1 of Science Central, Newcastle, UK

There is considerable choice in how to control each of these flexible assets in order to provide services to the grid at the point of connection whilst also providing value to 
the various stakeholders on the site. The characteristics of each is described below and summarized in Table 1.

\section{Energy storage}

The ESS will be built to allow different cell chemistries to be evaluated in response to real grid disturbances and new control algorithms. The inverter is rated at $360 \mathrm{kVA}$, and is assumed to have a storage capacity of $100 \mathrm{kWh}$.

\section{Combined Heat and Power}

A gas turbine CHP plant will be built with an electrical rating of $2000 \mathrm{~kW}$ and heat rating of $6000 \mathrm{~kW}$. Since the gas will be supplied via the national gas networks, it is assumed that this power can be supplied at all times. The heat generated will supply a heat network on the site which is not the subject of this paper.

\section{Electric vehicle charging station}

The site is to have six rapid EV chargers, and it is possible that adjacent to these will be a smart EV charging station. For the purpose of this study, it is assumed that an average of 45 EVs arrive for smart charging each day with a standard deviation of 3 cars. The EVs arrive at 09:00 and leave at 18:00 with a standard deviation of 1.2 hours. Each charge point is rated for $7 \mathrm{~kW}$ demand, and $3 \mathrm{~kW}$ vehicle to grid. The EVs are assumed to each have a battery of $24 \mathrm{kWh}$, which arrives with an average SOC of $53 \%$ with a standard distribution of $15 \%$ [13]. On departure the vehicles are assumed to leave with a SOC of between $80 \%$ and $100 \%$. Using these statistical distributions, a MonteCarlo study was undertaken to find the maximum aggregate power and energy limits that could be realised from the smart charging $\mathrm{EV}$ fleet. Using the ideas presented in [14], [15] and [16], it is assumed that an algorithm could exist to allow full flexibility within the aggregate power and energy curves presented in Figure 3, which is based on the 5th and 95th percentiles for maximum and minimum curves respectively. The EVs in aggregate can therefore be imagined similar to an ESS with dynamic power and energy ratings.

\section{Building demand side management}

As the site progresses, numerous commercial and residential buildings will be erected to include Heating, Ventilation and Air Conditioning (HVAC) DSR capabilities. The first building already on site is The Core, and the second building currently under construction is the Urban Sciences Building (USB).

Both buildings are to be heated using electrical pumps and the site heat network. A MATLAB Simulink model has been built for both buildings allowing the temperature feedback from DSR calls to be estimated. It was assumed the air condition deteriation takes place at the same rate as the heat energy dissipates to the external atmophere.

For the purposes of this study, it was assumed that the Core needs $31 \mathrm{~kW}$ and the USB needs $240 \mathrm{~kW}$ to maintain a constant temperature and air condition, based on an engineering judgement that HVAC DSR can achieve up to $33 \%$ reduction in a buildings demand [17]. The minimum power for each building was set to $0 \mathrm{~kW}$ (representing an effective generating power of $31 \mathrm{~kW}$ and $240 \mathrm{~kW}$ respectively). The maximum power demand was set to 70 $\mathrm{kW}$ for the Core and $500 \mathrm{~kW}$ for the USB. For an allowable temperature variation of $4^{\circ} \mathrm{C}$, the model estimated the Core and USB to have an effective storage capacity of $9 \mathrm{kWh}$ and $23 \mathrm{kWh}$ respectively.

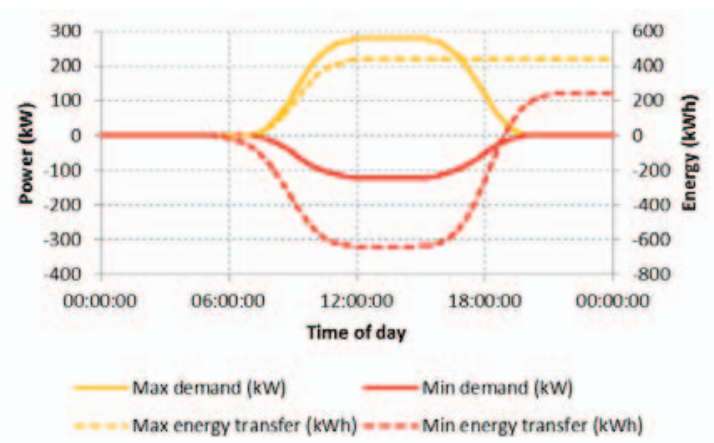

Figure 3: Dynamic time of day Power and Energy ratings of a smart $\mathrm{EV}$ charging station

Table 1 Summary of flexible asset characteristics

\begin{tabular}{|c|c|c|c|c|c|}
\hline & \multicolumn{3}{|c|}{ POWER $(\mathrm{kW})$} & \multirow[b]{2}{*}{$\begin{array}{c}\text { ENERGY } \\
\text { CAPACITY } \\
(\mathrm{kWh})\end{array}$} & \multirow{2}{*}{$\begin{array}{c}\text { TIME TO } \\
\text { CHARGE } \\
0 \% \text { TO } \\
100 \% \text { SOC } \\
\text { (Minutes) }\end{array}$} \\
\hline & Min & $\begin{array}{c}\text { Power to } \\
\text { maintain } \\
\text { constant } \\
\text { VSOC }\end{array}$ & Max & & \\
\hline $\begin{array}{l}\text { Energy } \\
\text { storage }\end{array}$ & -360 & 0 & 360 & 100 & 17 \\
\hline $\mathrm{CHP}$ & 0 & - & 2000 & - & - \\
\hline $\begin{array}{l}\text { EV Charging } \\
\text { (at 12.00) }\end{array}$ & -120 & 0 & 280 & 1077 & 231 \\
\hline $\begin{array}{c}\text { The Core } \\
\text { DSR }\end{array}$ & 0 & 31 & 70 & 9 & 14 \\
\hline USB DSR & 0 & 240 & 500 & 69 & 16 \\
\hline $\begin{array}{c}\text { Aggregation } \\
\text { of whole site } \\
\text { (at 12.00) }\end{array}$ & -480 & 271 & 3210 & 1255 & - \\
\hline
\end{tabular}

\section{SKOLTECH CAMPUS [18]}

The Skolkovo Institute of Science and Technology (Skoltech), Russia, are also developing a new campus similar to Science Central, hence the collaboration between Newcastle and Skoltech for this paper. The new campus is expected to accomodate 2,772 people over $133,000 \mathrm{~m}^{2}$ of floor space by 2020 .

\section{PLANT CONTROL}

The EFR service requires full requested output to be delivered for at least 9 seconds with just one second of notice. Despite this short duration, National Grid's initial analysis of frequency data indicates that the optimal battery capacity is that which corresponds to a 45 minute duration ( $0 \%-100 \%)$ [8]. It can be seen in Table 1 that only the EVs, which are not available at all times, have a 
duration above this. All the other assets have a duration significantly below 45 minutes. A control scheme has been developed to combine the high power ratings of the DSR and ESS with the high energy rating of the EVs, through intelligent energy management to ensure that the aggregate maximum power of the site is realisable, with little to no notice. The control scheme is designed to be scalable such that any flexible asset can be utilised. Each asset is considered in a form similar to ESS and the equivelent Virtual State of Charge (VSOC) is used as a common currency across the different types of assets with varying characteristics, that could otherwise be difficult to compare like for like.

In order to realise a power request, an asset must have energy available within its storage. By targeting 50\% VSOC, an asset without any prior knowledge of the service can maximise the amount of time a power request can be delivered for. During the service however, the VSOC will deviate from $50 \%$ at varying rates for each asset dependent upon their power and energy ratings. To maximise the power availability, all assets should approach their energy capacity limits at the same time. To implement these ideas, the time each asset can deliver maximum (positive or negative) power for is considered. The asset that can deliver for the longest period of time is used primarily for its energy and no target VSOC is set. All other assets are used primarily for their power and assigned a $50 \%$ VSOC target, unless the energy asset is approaching its VSOC limits in which case the energy of these assets is needed. In this situation, the power assets are assigned a VSOC target that would result in reaching their VSOC limit at the same time as the energy asset. A single fuzzy logic control surface is used mulitple times, once for each asset as shown in the block diagram of Figure 4. Fuzzy logic allows multiple variables to be considered at once, similarly to human thinking, and an intelligent decision to be made [19]. In this implementation, it ensures the overall requested microgrid power is delivered whilst managing the internal energy of individual assets to be as close as possible to their respective SOC targets. Each controller has three inputs :

- Output power - the output of the asset's fuzzy logic controller is fed back as a reference signal to be increased or decreased based on the error and SOC difference.

- Error - the power outputs of all assets are summated and compared against the total microgrid desired power output. The resulting error is fed into all fuzzy logic controllers.
- $\quad$ SOC difference - the difference between an assets SOC and its target SOC.

Fuzzy logic rules were created to prioritise the reduction of the error so the correct power output is delivered. At high power requests the error is picked up faster or slower depending on the SOC difference. When the power request and error are both low, the rules try to reduce the SOC difference. Therefore, a secondary control brings all assets towards their target VSOC if possible. The 4-dimensional control surface, with axes in per unit, is shown in the three 3-dimensional figures of Figure 5.

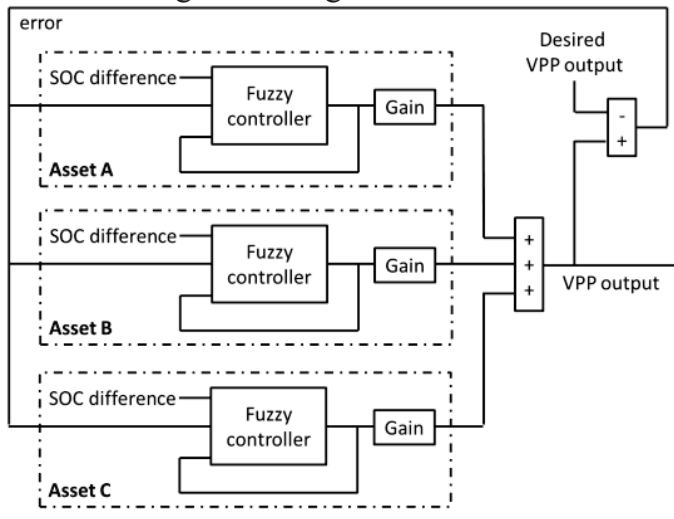

Figure 4: Block diagram of the scalable fuzzy logic based control

\section{CASE STUDY RESULTS AND DISCUSSION}

In order for potential EFR providers to demonstrate their offering, National Grid has published system frequency data at a one second resolution. One representative day has been simulated using this data, in conjunction with Figure 1 and the proposed control algorithm.

The distribution of the VPPs real power output dependent upon frequency, one second after each control set-point is given, is shown in Figure 6.

The aggregate load of the VPPs flexible assets is shown in Figure 7 along with each assets VSOC. The same study was undertaken without managing the VSOC of the assets, shown in Figure 8. During the day of simulation there was 11 minutes when a service could not be realised, during which the service was requested for 5 minutes. The deadband of Figure 1 could have been used to ensure VSOC when the assets are operating individually and without coordination, however with the proposed algorithm this is not required meaning the deadband could be used to layer other commercial services, thus increasing revenues. Furthermore, it can be observed in Figure 7 that the VSOC for the ESS, Core and USB remain close to
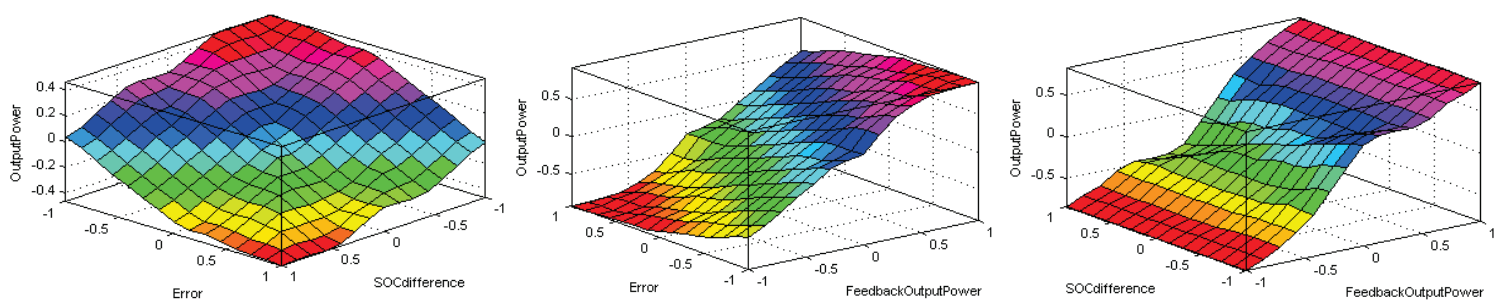

Figure 5: Fuzzy logic control surface (all axes per unit) 
$50 \%$ with a relatively large headroom of storage capacity unutilised. This suggests that by using the proposed control algorithm either; the storage capacities could be minimised reducing initial capital expenditure, or power ratings increased maximising potential EFR revenues.

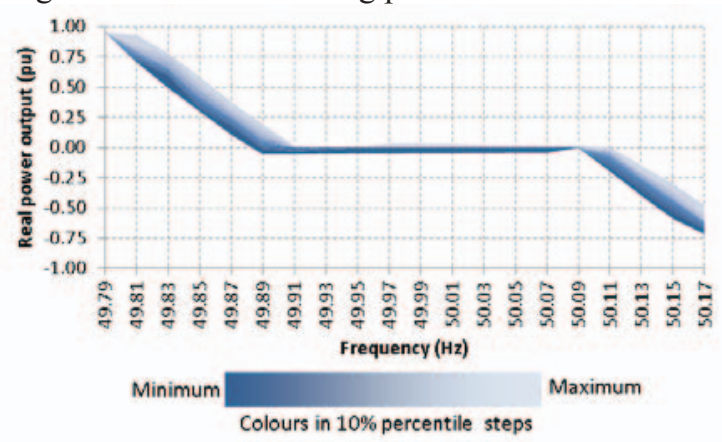

Figure 6: Distribution of realized service delivery one second after its request, dependent upon frequency, for the simulation day

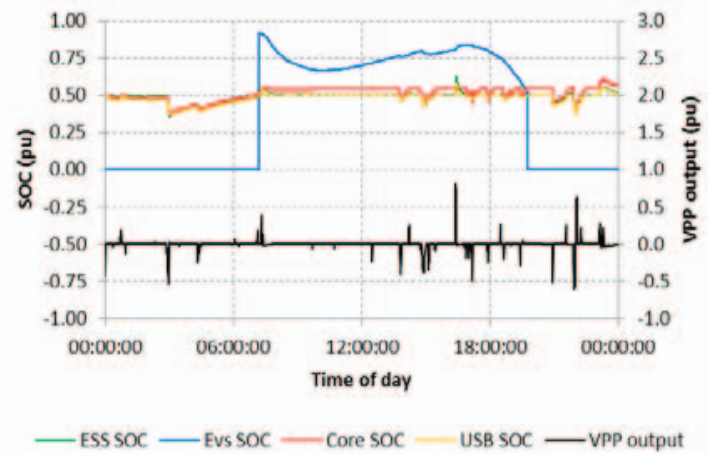

Figure 7: Aggregate load of the VPPs flexible assets and their SOC

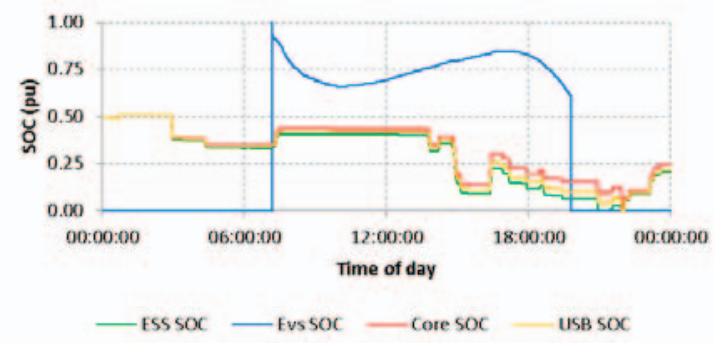

Figure 8: SOC of assets delivering the service without coordination

The proposed algorithm successfully maximizes power availability, however it does this without considering the economical or environmental costs associated with the use of each of the assets. Incorporating these attributes to find a good compromise between availability, economic and environmental cost is the subject of future work.

\section{REFERENCES}

[1] HM Treasury, 2008, Climate Change Act

[2] European Wind Energy Association, "Wind in power: 2015 European statistics", February 2016

[3] P. Trichakis et al, 2008, "Distributed control approach for small-scale energy zones", IMechE Journal of Power and Energy, Vol 222 No A2

[4] D. Pudjianto et al, 2005, "Investigation of regulatory, commercial, economic and environmental issues in microgrids", Int Conference on Future Power Systems

[5] D. Prudjianto et al, 2007, "Virtual power plant and system integration of distributed energy resources", IET Renewable Power Generation, Vol 1, Issue 1

[6] O. Anuta et al, 2014, "An international review of the implications of regulatory and electricity market structures on the emergency of grid scale electricity storage", Renewable and sustainable energy reviews, Vol 38, pp. 489-508.

[7] P. Wang et al, 2014, "Integrating electrical energy storage into coordinated voltage control schemes for distribution networks", IEEE Trans on Smart Grid, Vol 5, Issue 2

[8] [Online] www.nationalgrid.com

[9] [Online, published 14 March 2014] www.gov.uk/government/news/electricity-marketreform-capacity-market-design

[10] D. Greenwood et al, 2015, "Scheduling power and energy resources in the smarter network storage project", $23^{\text {rd }}$ Int conference on electricity distribution, paper 0824

[11] [Online] www.newcastlesciencecentral.com

[12] [Online, published 7 May 2015], www.ncl.ac.uk/eee/about/news/item/energy-storagetest-bed-is-officially-switched-on-copy

[13] M. Neaimeh et al, 2015, "A probabilistic approach to combining smart meter and electric vehicle charging data to investigate distribution network impacts", Applied Energy, Vol 157, pp. 688698.

[14] T. Ma et al, 2012, "Optimal charging of plug-in electric vehicles for a car park infrastructure", IEEE Trans on industry applications

[15] M.G.Vaya et al, 2012, "Centralised and decentralized approaches to smart charging of plug-in vehicles", IEEE Power and Energy society general meeting

[16] R. Lamedica et al, 2015, “An energy anagement software for smart buildings with V2G and BESS", Sustainable cities and society, Vol 19, pp. 173-183

[17] Demand Response Research Center, 2007, "Introduction to Commercial Building Control Strategies and Techniques for Demand Response"

[18] [Online, published 17 February 2014] http://www.skoltech.ru/en/2014/02/skoltech-campuswill-open-its-doors-in-2015/

[19] C.C. Lee, 1990, "Fuzzy Logic in Control Systems: Fuzzy Logic Controller - Part 1", IEEE Transactions on systems, man, and cybernetics, Vol 20, No 2. 